\title{
Fuentes orales e historia obrera: el caso de los zapateros en Costa Rica*
}

\section{Victor Hugo Acuña Ortega}

La particularidad de las reflexiones que siguen está condicionada por los límites de nuestra experiencia. ${ }^{1}$ Nosotros somos principalmente practicantes de la historia obrera y apenas usuarios de la historia oral. A ella hemos llegado desde el estudio histórico de las clases trabajadoras y condicionados por un largo contacto con la fuente escrita. Por esta razón hemos visto la historia oral como una técnica o un instrumento que nos permite enriquecer la historia obrera con otro tipo de fuente. ${ }^{2}$ Nuestro interés no es por tanto ni el del "archivista de la palabra", ni el del estudioso de la tradición oral como expresión de la cultura popular, ni el del antropólogo o el sociólogo que hace de la historia de vida su principal instrumento para conocer e interpretar la estructura y la dinámica sociales. Tal aproximación instrumental a la fuente oral comporta la ventaja de que siempre pasa por un proceso de confrontación con la fuente escrita, pero conlleva el riesgo de mal interpretar la especificidad del testimonio y de subestimar su riqueza.

Por otra parte, nuestra práctica de la historia obrera y nuestro uso de la historia oral han estado insertos en un interés ético-político de recuperar la memoria popular. Nos ha ocupado la historia obrera porque hemos querido rescatar el papel de las clases trabajadoras en el desarrollo histórico de nuestro país y nos aproximamos a la historia oral con el objetivo inicial de rescatar los recuerdos de trabajadores que participaron en luchas y conflictos que tuvieron gran relevancia en la historia contemporánea de Costa Rica. Esta legítima intención ético-política tuvo como efecto, en las primeras etapas de nuestro trabajo, la insistencia constante en ver a los sectores populares como gestores o actores y en considerar su memoria más como monumento (objeto de admiración y conmemoraciọn), que como documento o instrumento de análisis. No en vano en los inicios nuestra intención era recopilar y publicar recuerdos (salvar la memoria popular) y reunir algunas biografias de trabajadores destacados por su trayectoria militante. Tal visión ingenua de la memoria popular y de la técnica que permite restituirla implica un doble riesgo: reducir el recuerdo a una mera ilustración de la postura ideológica del investigador y, potencialmente, propagar una visión heroica e inclusive hagiográfica de la historia obrera.

* Ponencia presentada en el Primer Encuentro de Historiadores Orales de América Latina y España, Instituto de Investigaciones Dr. José María Luis Mora, 23-25 de septiembre de 1988.

' Nuestra investigación se ha desarrollado en el marco del proyecto sindical del Centro de Estudios para la Acción Social (CEPAS) en el que hemos contado con el apoyo, el estímulo y la crítica de los companeros Elisa Donato, Carlos Castro y Mauricio González.

"En esta optica véase Peter Winn, "Oral History and the Factory Study: New Approaches to Labor History", Latin American Research Review, vol. XIV, núm. 2, 1979. 
No obstante, en el transcurso de la investigación, logramos convertir la fuente oral en material para la reconstrucción de las circunstancias de formación de la conciencia obrera ${ }^{3}$ y en instrumento que nos permitió interpretar los vínculos que existen entre la vida cotidiana, el proceso de trabajo y las características de la organización sindical. ${ }^{4}$ A partir de este momento hemos empezado a descubrir las posibilidades y los limites de la fuente oral en la construcción de una historia de los trabajadores.

Esos limites y posibilidades aparecen sobredeterminados por el tipo de sujetos en el que centramos nuestro estudio. En efecto, hemos estado trabajando no con cualquier tipo de trabajador sino con militantes y dirigentes del Sindicato de Zapateros de Costa Rica. Esta selección estuvo predeterminada por nuestras ya indicadas opciones ético-politicas pero también se fundó en otro tipo de consideraciones. La primera emanó del estudio del presente y de la constatación de las debilidades de la organización sindical de los obreros industriales de la Costa Rica actual; debilidades que conocía y sufría la dirigencia del Sindicato de Zapateros con la que hemos mantenido una relación permanente a lo largo de la investigación. El presente nos condujo, por contraste, al pasado, pues precisamente en las décadaś de 1930 y 1940 los zapateros y su sindicato habian mostrado una gran actividad de militancia laboral y política. Aquí es donde aparece la segunda consideración: la categoria ocupacional de los zapateros y su organización sindical tuvieron una posición central en los movimientos sociales y en las luchas políticas del periodo 1931-1948. El Sindicato de Zapateros constituyó el sector más avanzado del movimiento sindical de aquel periodo y los trabajadores del calzado aportaron numerosos activos e influyentes militantes y dirigentes al Partido Comunista, precisamente en una fase en que éste tuvo una gran resonancia en la vida nacional. En consecuencia, más allá de nuestros valores el estudio de los zapateros constituye de por sí una cuestión relevante en la investigación del proceso de formación de la clase trabajadora costarricense.

En suma, nuestros testimonios presentan las posibilidades y los límites de la fuente oral, bastante conocidos pero sobreestimados, para bien y para mal, ya que provienen de individuos que protagonizaron, y no sólo padecieron, la historia y que adquirieron una visión del mundo coherente y totalizante con su adhesión al movimiento comunista de la época. ${ }^{5}$

El material que poseemos consiste en una decena de historias de vida, en tres entrevistas colectivas realizadas con las mismas personas con quienes hicimos las historias de vida, y en una autobio-

\footnotetext{
${ }^{3}$ Víctor Hugo Acuña Ortega, "La formation de la conscience syndicale et politique chez les ouvriers de la chaussure au Costa Rica (1920-1934)", ponencia presentada en el VI Congreso Internacional de Historia Oral, Oxford, 11-13 de septiembre de 1987.

+ Idem, "Vida social, condiciones de trabajo y organización sindical: el caso de los zapateros en Costa Rica, 1934-1955", ponencia presentada en el II Seminario de Historia Sindical, FLACSO/INAH, Tlaxcala, 30 de noviembre-4 de diciembre de 1987.

Sobre los problemas del militante obrero como informante, véase Liliana Lanzardo, "Class Consciousness and the Fiat Workers of Turin since 1943", en Our Common History: The Transformation of Europe, edicion de P. Thompson y M. Burchardt, Londres, Pluto Press, 1982.
} 
grafía escrita por el secretario general del Sindicato de Zapateros ${ }^{6}$ años antes de que iniciáramos nuestra investigación. Es pertinente indicar que el dirigente obrero se ha preocupado desde tiempo atrás por conservar y transmitir por medio de distintos escritos la historia del Sindicato, de manera que nuestra inquietud por la historia del Sindicato ha encontrado en esta persona eco, apoyo y orientación.

Es conveniente advertir que también hemos recopilado información escrita, sobre el Sindicato y sobre los zapateros en general, que procede de fuentes periodísticas, de documentos de archivos, de materiales censales y de las actas de la junta directiva del Sindicato. A pesar de que aún no hemos procedido a efectuar una confrontación exhaustiva y sistemática entre esas fuentes y la fuente oral, estamos en capacidad de hacer un balance preliminar de lo que ha significado para nosotros el uso de las fuentes orales.

Conscientes de que quien no se ha informado previamente no puede realizar encuestas orales, adquirimos un primer bagaje de conocimientos sobre la historia de los zapateros y de su sindicato en Costa Rica por diversos medios: lecturas generales sobre la historia obrera y el Partido Comunista de Costa Rica durante el mismo periodo, cierta tradición oral que flota en el ambiente costarricense y da a los zapateros fama de comunistas, una historia del Sindicato de Zapateros redactada por uno de sus dirigentes, que fue de especial orientación, y la autobiografía ya citada que aporta información valiosa; también debemos mencionar diversas conversaciones con el ya citado secretario general del Sindicato quien es una especie de memoria viviente de la organización. Con estas bases nos lanzamos a la recopilación de historias de vida y a la realización de los talleres en los que efectuamos las entrevistas colectivas a los viejos zapateros.

La primera contribución que innegablemente nos ha dado la historia oral ha sido el desarrollo del propio proceso de investigación. ${ }^{8}$ Nuestras intuiciones, hipótesis y problemas de partida deben muchísimo al diálogo continuo que hemos mantenido con el secretario general del Sindicato. Las entrevistas nos han permitido localizar algunas fuentes: libros de actas, fotografías, un hermoso álbum con fotos, recortes periodisticos, carteles de los equipos de futbol y de ciclismo del Sindicato, y versos y canciones de corte militante escritos por uno de nuestros entrevistados. Aunque al principio el contacto con los entrevistados fue posible gracias al Sindicato, algunos trabajadores del primer grupo de entrevistados nos han permitido ponernos en comunicación con otros informantes. en una especie de efecto de bola de nieve. De esta manera, el propio proceso de recopilación de testimonios ha servido para en-

" Juan Rafael Morales, “Autobiografia", Concurso Nacional de Autobiografias de Obreros y Artesanos, Heredia, Costa Rica, Universidad Nacional, 1982, manuscrito fotocopiado.

7 Resumen histórico. 50 años de luchas del Sindicato Nacional de Trabajadores del Calzado. Cueros y Similares, manuscrito, 1984.

"Una constatación análoga se encuentra en: Lutz Niethammer, "Oral History as a Channel of Communication between Workers and Historians", en Our Common History..., op. cit. 
contrar nuevos informantes. ${ }^{9}$ En suma, el contacto con los sobrevivientes de una época histórica no sólo ha servido para recuperar sus recuerdos sino también para encontrar otros tipos de vestigios. Esto no hubiera sido posible si hubiéramos limitado nuestras pesquisas a los archivos públicos y a los fondos hemerográficos.

La fuente oral, decíamos, ha contribuido a formular nuestra problemática, nuestras interpretaciones y a descubrir aspectos desconocidos de la realidad. La importancia que tuvieron las particulares condiciones del proceso de trabajo (que imperaban en los talleres de zapatería de Costa Rica en la primera mitad del siglo) en el comportamiento sociopolítico de los zapateros, nos fue revelada por la fuente oral. Ella nos ha permitido aproximarnos a la vida cotidiana en el mundo del trabajo, pero sobre todo nos ha posibilitado conocer el significado que los zapateros le confieren para explicar su radicalismo social y político.

Durante los años de beligerancia del Sindicato de Zapateros y de influencia del Partido Comunista en la vida nacional, fue emitida la legislación social costarricense. Alrededor de las Reformas Sociales de la década de 1940 se ha tejido toda una historia oficial que comparten los diversos sectores políticos del país, incluidos los comunistas. No en vano los distintos actores sociales y políticos las denominan "conquistas sociales" y las conciben como un pilar de la Costa Rica contemporánea. No obstante, poco se ha investigado sobre los efectos inmediatos que tuvo sobre la vida de los trabajadores dicha legislación social. Es aquí donde el testimonio oral ha mostrado su utilidad porque las entrevistas con los zapateros nos han revelado que la legislación social y en particular el Código de Trabajo emitido en 1943 directa e indirectamente tuvo efectos negativos sobre los zapateros. Por un lado, en forma directa, afectó el poder del Sindicato, pues eliminó la sindicalización obligatoria y estableció la libre afiliación. Por otro lado, indirectamente, favoreció la pérdida de cohesión del grupo y de la organización, ya que la parte patronal enfrentó la nueva legislación disolviendo los talleres y adoptando la modalidad del trabajo a domicilio. Este cambio en el proceso de trabajo inducido indirectamente por la legislación social tuvo efectos negativos sobre la capacidad de lucha y de organización de los zapateros. Ciertamente que este proceso en toda su complejidad y precisión debe ser establecido con otro tipo de fuentes, algunas de ellas disponibles, como las actas del Sindicato y otras sobre historia de empresas que aún no hemos podido localizar. En todo caso, gracias a la historia oral hemos vislumbrado un horizonte que nos era desconocido.

La fuente oral también nos ha ayudado a ver con relatividad ciertas interpretaciones de nuestra historia firmemente extendidas. El movimiento obrero sindical y político dirigido por el Partido Comunista fue derrotado en una corta guerra civil que hubo en Costa Rica después de 1948. A partir de esa fecha, estas organizaciones perdieron influencia en la vida nacional de manera duradera y definitiva. Usualmente se atribuye este declive del comu-

\footnotetext{
9 Una experiencia similar se encuentra reportada en: Ives Lequin y Jean Métral, "A la recherche d'une mémoire collective: les métallurgistes retraités de Givors", Annales (E.S.C.), año 35, núm. 1, enero-febrero, 1980.
} 
nismo a la derrota y a la represión que sufrió en y después de 1948. No obstante, la fuente oral nos ha permitido reconsiderar esta interpretación y valorar otros factores en la explicación del declive histórico del comunismo en nuestro pais. Así, lo que ocurrió después de 1948 debe ser atribuido más bien a cambios en las políticas estatales, a modificaciones en la estructura social, a procesos de movilidad ocupacional y en fin, a nuevos procesos de formación de la clase trabajadora costarricense. En este aspecto ha sido relevante no sólo la opinión de los entrevistados sino también su propia historia ocupacional que hemos establecido a partir de sus historias de vida. En suma, a partir de los testimonios nos hemos visto obligados a revisar interpretaciones sobre aspectos básicos del desarrollo de la Costa Rica contemporánea.

No hemos derivado de la fuente oral nuestra concepción de lo que debe ser la historia obrera. Ya antes de utilizarla sabíamos que la llamada historia del movimiento obrero suele ser sesgada, limitada e ideologizada. Por tal razón decidimos adoptar frente a la categoria ocupacional de los trabajadores del calzado una perspectiva de historia total. Así, hemos tratado de establecer todos los siguientes aspectos: condiciones laborales, procesos de trabajo, cambios tecnológicos de la rama, condiciones de vida y estratificación social interna del grupo; al lado de estas condiciones económicas hemos tratado de determinar sus formas organizativas, sus patrones de acción colectiva o de protesta social y sus modos de inserción y participación en la actividad política; de igual manera hemos intentado acercarnos a sus instituciones y prácticas culturales y a las formas y contenidos de su conciencia social; por último, nos ha preocupado el contexto y las relaciones sociales en que se encuentra inserta la categoría ocupacional en relación con el Estado, la Iglesia y los patronos; en suma, hemos intentado situar este grupo de trabajadores en el marco de un patrón de relaciones de clase que necesariamente remite a la dinámica de la totalidad social.

Siempre hemos tenido una visión de la clase social no como estructura o posición en relaciones estructurales, sino como proceso histórico de construcción de identidades en el marco de unas relaciones sociales de conflicto y cooperación, de dominación y resistencia, de explotación y negociación. El concepto de experiencia $^{10}$ ha sido por tanto central en nuestra manera de ver a los zapateros. Ellos han sido criaturas y creadores de condiciones y situaciones sociales históricamente cambiantes.

La fuente oral nos ha permitido confirmar y radicalizar nuestros supuestos teórico-metodológicos. Por ejemplo, nos ha permitido conocer cómo una serie de experiencias de diversa naturaleza condujeron a estos trabajadores a adoptar determinado comportamiento social y político. Fueron determinadas condiciones particulares y ciertos procesos históricamente contingentes los que llevaron a los zapateros entrevistados a hacerse comunistas. La formación de su conciencia no fue resultado de un ciego e irremediable determinismo estructural sino de una historia y de la manera en que esa historia incidió en unas vidas concretas. Los testi-

${ }^{10}$ Véase E. P. Thompson, La miseria de la teoria, Barcelona, Crítica, 1981, p. 253-263. 
monios de estos zapateros nos han mostrado que el radicalismo obrero no depende únicamente de la conducción de una vanguardia política y que la formación de la conciencia política obrera no necesariamente es introducida desde afuera como plantea el leninismo. Al contemplar la trayectoria ocupacional de nuestros entrevistados hemos podido adivinar que los procesos de formación de clase constituyen un perpetuo movimiento nunca cristalizado. En suma, la historia oral nos ha sometido a la dura prueba de establecer una relación más flexible y más productiva entre conceptos abstractos y vidas concretas. La fuente oral nos ha planteado el grave desafío de conjugar la "no uniformidad de la experiencia humana" con la pretensión de generalidad y de explicación global de la ciencia social. De igual manera, la historia oral nos ha obligado a reflexionar sobre las relaciones que existen entre la acción humana y los condicionamientos estructurales, entre libertad y necesidad en la historia. ${ }^{12}$ ¿Cómo produce la vida social individuos y trayectorias vitales? ¿Cómo producen los individuos la sociedad? ¿Cómo conforma un agregado de experiencias individuales un destino colectivo? Esas son preguntas que siguen asediando nuestro trabajo de investigación y que son alimentadas por el trabajo de recopilación de testimonios.

La fuente oral no sólo nos conduce a tensiones teóricas no fácilmente solubles sino que, de igual manera, introduce correcciones en nuestros presupuestos ideológicos. Sin lugar a dudas las personas que hemos entrevistado son en muchos aspectos excepcionales y admirables por su compromiso en la práctica y por su elevada conciencia. Ellos nos confortan en nuestra idea de que el pueblo también hace la historia. Sin embargo, a veces nos han inducido a olvidar que no todos los trabajadores, incluidos muchos de sus contemporáneos zapateros, han sido igualmente conscientes, comprometidos y luchadores. La contrapartida de este trabajador protagónico es el obrero aislado en su individualidad y cotidianidad con el cual no hemos tenido contacto. Nuestra historia nunca será completa mientras no seamos capaces de determinar lo que sentía y pensaba el obrero conformista o los zapateros (que los habia) claramente anticomunistas. Para ser exactos nuestros entrevistados nos han brindado alguna información de la existencia de ese tipo de trabajador pero desgraciadamente por un sesgo del entrevistador y por la posición ideológica del entrevistado hemos dejado en la sombra ese tipo humano. Ese silencio en el que hemos sido cómplices informante e investigador muestra el carácter irremediablemente subjetivo e incompleto que comporta la fuente oral. ${ }^{13}$ No obstante, las entrevistas nos han permitido constatar que aun esos trabajadores excepcionales son seres humanos de carne y hueso. A este respecto la propia fuente oral nos ha ayu-

11 "If there is one aspect of human life which oral investigation reveals time and time again, it is the non-uniformity of experience, the extraordinary variety of links between individuals and their environment, no matter how limited that environment might be". (David Ellwood y Anna Bravo, "Oral History and Resistance History in Italy", en Our Common History..., op. cit., p. 291.)

${ }_{12}$ Vease: Daniel Bertaux, "Stories as Clues to Sociological Understanding: The Bakers of Paris", en Our Common History..., op. cit.

${ }^{13}$ Alessandro Portelli, "Las peculiaridades de la historia oral", Tarea, núm. 11, noviembre de 1984. 
dado a terrenalizar nuestra visión idealizada de la clase trabajadora. El héroe lúcido, incansable, de tiempo completo, e inclaudicable hasta la muerte es una rara avis de la sociedad y de la historia. No obstante, igualmente raro es el ser humano que es únicamente una patética marioneta de las estructuras, de las determinaciones y de la dominación. Un uso lúcido de la fuente oral nos puede prevenir de los extremos del romanticismo populista y del pesimismo elitista. En última instancia, la fuente oral, la historia obrera y la recuperación de la memoria popular sólo tienen un real interés en la medida en que aporten a la producción de nuevos saberes más críticos. ${ }^{14}$

La fuente oral es subjetiva y relativa, lo cual no significa como lo hemos visto que sea enteramente inútil. Desde el principio aceptamos que los trabajadores nos brindarian no "lo que realmente sucedió", sino su punto de vista de lo sucedido, punto de vista que se formula desde el presente y al final de una larga vida. En este sentido, aceptamos que la perspectiva de estos trabajadores está condicionada por su formación comunista y por la historia oficial del partido al que han pertenecido. Por ejemplo, su manera de contarnos cómo se hicieron comunistas está condicionada por el hecho de que hasta el presente afirman conservar esa adhesión ideológica. No obstante, su verdad subjetiva nos ha iluminado elementos objetivos, por ejemplo, el lugar central que juega en su formación ideológica y en su vida militante el mundo del trabajo. El consenso que al respecto han mostrado nos autoriza a estimar que su interpretación es correcta. De igual manera, nos parece que su explicación sobre cómo se hicieron comunistas descubre elementos esenciales aunque aceptamos que es incompleta puesto que ningún actor, por más lúcido y crítico que sea, nunca es totalmente consciente de lo que ha sido su propio devenir.

Por otra parte, sus prejuicios y sus silencios también nos han enseñado. Por ejemplo, la ausencia del anarquismo en sus recuerdos y los prejuicios negativos que algunos de ellos nos han manifestado al respecto han servido para recordarnos su formación comunista y para indicarnos que éste es un problema que permanece abierto en la agenda de investigación. De igual modo, su resistencia, su temor o sus insinuaciones indirectas respecto a su participación en los procesos electorales anteriores a 1948 nos han permitido inferir que protagonizaron actividades electorales de carácter fraudulento. En un país que ha llegado a sacralizar la libertad y la pureza del sufragio es natural que hoy resulte embarazoso confesar que en el pasado se participó en fraudes, sobre todo si se toma en cuenta que en la guerra civil de 1948 esa fue una de las principales acusaciones que se esgrimieron contra los comunistas. Esta especie de sentimiento de culpa es normal, aunque los mismos entrevistados podrian menguarlo señalando que el fraude no fue práctica exclusiva de los comunistas, sino algo consustancial a la política de la época, practicado por todos los partidos y favorecido por todos los gobiernos.

it Victor Hugo Acuña Ortega, "Cuestiones de memoria popular e historia social", en Memoria y Cultura Popular Costarricense, San José, CENAP, 1986. 
La producción de fuentes orales en la medida en que es una relación de dos comporta una dimensión de fascinación y seducción. ${ }^{15}$ Indudablemente nosotros hemos sucumbido a tal seducción. La visión idealizada y gloriosa que los zapateros tienen de su sindicato y de sus luchas se ha apoderado de nosotros. No nos ha sucedido lo mismo con el Partido Comunista porque frente a él hemos tenido desde antes del inicio de la investigación una actitud crítica y de desconfianza frente a su versión oficial de la historia. No obstante la propia fuente oral ha introducido correcciones puesto que los mismos viejos zapateros nos han mostrado indicios, las más de las veces involuntariamente, de que el Sindicato empezó a tener diversos tipos de problemas años antes de la guerra civil y los años de represión.

La utilidad y la necesidad de la confrontación de la historia oral con otros tipos de fuentes nos ha sido revelada en las actas de la junta directiva del Sindicato en donde hemos podido verificar una historia más prosaica y necesariamente menos maravillosa.

Nuestra fascinación por la vida militante de estos trabajadores nos llevó a proponerles un contrato de comunicación y de formulación de recuerdos que ha estado centrado sobre esta dimensión de sus vidas. En este sentido la información que hemos producido lleva la impronta de este sesgo. Hemos aprendido más sobre la vida pública que sobre la vida privada de estos trabajadores, más sobre su vida cotidiana laboral que sobre su vida cotidiana familiar. Probablemente si hubiéramos planteado nuestra investigación en otros términos tendriamos otro tipo de recuerdos; para decirlo de alguna manera hemos puesto más el acento en que fueron comunistas y no en que fueron obreros, pero pudimos haber puesto el énfasis en su condición de obreros y no en su condición de comunistas. Tal limitación de nuestro trabajo podría ser corregida ampliando la "muestra" de nuestros informantes pero de todas maneras el problema es, en última instancia, insoluble porque es inherente a la encuesta oral y en general a toda estrategia de investigación. En efecto, no hay que olvidar que cualquier investigación condiciona el tipo de fuente que va a utilizar por el tipo de problemática, objetivos e hipótesis que han sido formulados en su punto de partida. Las fuentes y el modo de su utilización dependen de supuestos previos.

Existen diversas maneras de utilizar el testimonio oral. ${ }^{16} \mathrm{La}$ más elemental e ingenua que suscita nuestro mayor escepticismo es la que consiste en simplemente recopilar el testimonio oral y traducirlo al lenguaje escrito con fines edificantes, aleccionadores y movilizadores. Esto es lo que hemos llamado el testimonio como monumento. Este uso cae por debajo de la problemática de la investigación social. En este caso el entrevistador aparentemente se inmola en el altar de la voz del pueblo incurriendo en muchas formas de candidez que resulta dudoso tengan un contenido liberador. Otra forma de utilizar el testimonio un poco más elaborada

${ }^{15}$ Mercedes Vilanova, "Introducción", en El poder en la sociedad. Historia y fuente oral, edición de Mercedes Vilanova, Barcelona, Antoni Bosch Editor, 1986.

${ }_{16}$ Sobre los distintos modos de utilización del método biográfico en las ciencias sociales puede consultarse: Franco Ferrarotti, "Acerca de la autonomia del método biografico", en Jean Duvignaud, comp., Sociologia del conocimiento, Mexico, FCE, 1982. 
es aquella que consiste en transcribirlo para luego ordenarlo temáticamente. Aqui, aunque el esfuerzo del investigador es mayor, el valor del testimonio se reduce al de ilustración o ejemplificación de ciertos aspectos considerados significativos por el investigador. Estas dos formas de utilización de la fuente oral expresan una especie de fascinación del testimonio sobre el investigador y manifiestan su dificultad para convertir esta fuente en instrumento de producción de un conocimiento social crítico. En última instancia, estos modos de utilización del testimonio dependen de la capacidad de narrar del informante y de la alquimia literaria del entrevistador y de sus inclinaciones ideológicas.

La primera forma de utilización cientifica del testimonio consiste en convertirlo en fuente (como cualquier otra fuente histórica) con la intención de resolver una problemática relevante desde el punto de vista de la investigación. Es en esta modalidad que nosotros hemos sido usuarios de la fuente oral. Hemos tomado fragmentos de los distintos testimonios, como el historiador tradicionalmente opera con la fuente escrita, con el fin de aclararnos algún aspecto de la condición obrera. En otras palabras, conservando las precauciones pertinentes, hemos buscado en la fuente oral su aporte factual, entendido lo factual no como eventos específicos sino como procesos iterativos de la cotidianidad, como procesos globales de un periodo o como relaciones características de una situación social. En otras palabras, hemos pretendido utilizar la fuente oral en aquellos aspectos en que lo subjetivo es susceptible de algún tipo de control. Por otra parte, hemos utilizado el testimonio para resolver problemas en los que lo que estaba en juego era precisamente lo subjetivo, en donde lo que queríamos conocer eran subjetividades, como por ejemplo las condiciones que llevaron a nuestros informantes a hacerse comunistas. No obstante, incluso en este caso hemos aceptado que sólo hemos percibido un aspecto del proceso puesto que sus aspectos inconscientes no fueron determinados. Debemos agregar que las preguntas que hemos formulado a la fuente oral pueden ser parcial o indirectamente contestadas por otro tipo de fuente o pueden eventualmente ser sometidas a prueba por medio de la historia comparada.

En suma, hemos intentado domeñar la masa heterogénea de recuerdos contenida en nuestros testimonios formulándoles algunas preguntas que nos parecían relevantes. Dicho de otro modo, hemos insertado la fuente oral en el flujo de la clásica estrategia del proceso de investigación social.

No obstante, nuestro procedimiento comporta una primera debilidad o limitación. Hemos hecho abstracción de que la historia oral y las historias de vida adoptan una forma narrativa, y que, como discurso, están sometidas a ciertos preceptos o códigos formales y de sentido. La fuente oral es un discurso y como tal puede ser analizado, criticado e iluminado por las disciplinas que se ocupan del estudio de los discursos. Hemos olvidado que los hechos que hemos recogido han sido vestidos con ciertas formas lingüisticas, gramaticales y semánticas. ${ }^{17}$ Es en este punto donde se ponen

17 "...for the essential point is that interviews carry two kinds of clue, firstly through the explicit information which is conveyed and secondly, the form of telling". (Paul Thompson, "Introduction", en Our Common History..., op. cit., p. 17.) 
en evidencia las limitaciones de nuestra formación como historiadores y las ingenuidades a que nos condenan cuando nos enfrentamos a la oralidad y a la escritura no como soportes de datos sino como sistemas de signos. ${ }^{18} \mathrm{~A}$ la conclusión que llegamos es que usuarios o practicantes de la historia oral debemos dedicarnos a la adquisición de algunas herramientas de la teoría literaria y de la semiologia. Sólo de este modo podremos valorar adecuadamente la utilidad de esta fuente.

Otra forma de utilizar la historia oral o en particular las historias de vida que nosotros no hemos practicado consiste en descubrir lo que podriamos llamar la lógica interna de una trayectoria vital. En este caso la fuente oral no se utiliza para entresacar información, sino que se la analiza globalmente para encontrar en ella algunos elementos de explicación de esa trayectoria especifica, que son simultáneamente elementos que nos permiten comprender la estructura y la dinámica de la vida social. Probablemente valga la pena tomar una de las historias de vida que hemos recopilado y hacer una lectura de ella como expresión del desarrollo histórico costarricense a lo largo del presente siglo.

En nuestra corta experiencia como usuarios de la historia oral podemos afirmar que ella es una firme aliada de la historia obrera como historia social y cultural de las clases trabajadoras. Sus contribuciones son tan variadas que sería insensato no sacar provecho de ellas. Pero así como es limitado hacer una historia obrera del siglo $\mathrm{xx}$ basada únicamente en fuentes escritas, igualmente es restrictivo hacer historia obrera exclusivamente con fuentes orales. En este caso lo que se impone es un diálogo entre los dos tipos de fuentes en donde la una ilumina la riqueza y las carencias de la otra. Hacer investigación histórica en diálogo con los actores es sumamente provechoso, a condición de considerar la palabra del actor como una palabra susceptible de crítica y de evaluación. La fuente oral contribuye a pluralizar las voces del pasado a las que está atento el historiador y esta pluralización debe inducir al investigador a adoptar una visión pluralista del valor de sus fuentes. No hay voz humana que sea deleznable, y del mismo modo ningún discurso es sagrado.

La fuente oral también puede contribuir a profundizar el espíritu crítico en las tareas de recuperación de la memoria popular. Una atenta escucha de la voz de los sin voz puede servir como antídoto a las idealizaciones que sobre todo en América Latina solemos hacer de ellos. Es iluso creer que nosotros somos apenas meros retransmisores de la voz popular. ${ }^{19}$ Esa voz, desde que nos es dicha a nosotros, ya no es simplemente la voz del pueblo sino su palabra requerida por nosotros. ${ }^{20}$ Más aún, cuando convertimos

${ }^{18}$ Sobre la historia oral y las historias de vida como discursos, véase Regine Robin, “Cede la historia oral la palabra a quienes están privados de ella, o es la historia de vida un espacio al margen del poder?", en El poder en la sociedad, op. cit.., p. 195-203.

19 En la encuesta oral siempre se plantea una relación de exterioridad y de interioridad, de complicidad con el hablante y de distancia crítica con lo que dice. Esto es lo que algunos denominan una "duplicidad insoslayable", véase: Anni Borzeix y Margaret Maruani, "La memoria como un objetivo de poder y la duplicidad insoslayable del oficio de sociólogo", en El poder en la sociedad, op. cit.

${ }_{20}$ Como dice Portelli, op. cit.: "La historia oral no es el lugar en donde la clase obrera hable por sí misma. En la historia oral -agrega luego- el control del discurso histórico permanece firmemente en manos del historiador..." 
esa voz en un texto escrito irremediablemente nos convertimos en traductores y las traducciones fieles, por supuesto, no existen. Historia oral, historia obrera y recuperación de la memoria popular sólo son posibles si libremente se hacen a dos, como el amor. 